\title{
Status Overview for Pacific Salmon Populations in the Eastern North Pacific Ocean
}

\author{
James R. Irvine', Andrew R. Munro², William Templin², Mary Thiess ${ }^{1}$, Sue Grant ${ }^{3}$, and Erik Neatherlin ${ }^{4}$ \\ ${ }^{1}$ Fisheries and Oceans Canada, Pacific Biological Station, 3190 Hammond Bay Road, Nanaimo BC V9T 6N7 \\ Canada \\ ${ }^{2}$ Alaska Department of Fish and Game, Division of Commercial Fisheries, 333 Raspberry Road, Anchorage, Alaska \\ 99518 USA
}

${ }^{3}$ Fisheries and Oceans Canada, 3-200 Annacis Parkway, Delta, BC V2M 6A2 Canada

${ }^{4}$ Washington Fish and Wildlife, 1111 Washington Street, SE Olympia, Washington 98501 USA

Keywords: Pacific salmon, stock status, Eastern North Pacific, abundance, North American salmon

Pacific Salmon in the eastern North Pacific (Fig. 1), dominated by Chum, Pink, and Sockeye Salmon, are at relatively high levels in terms of numbers and biomass, although there is evidence of recent declines (Fig. 2, Ruggerone and Irvine 2018). To assess the status of salmon in this region we assembled information gathered by American and Canadian researchers. In the US, salmon are primarily managed to provide sustained yield; spawner escapement goals are set for stocks, or aggregates of stocks, for each species within geographic areas. The proportion of stocks within an area that achieve these goals provides an indication of status for that return year. In Canada, salmon are primarily assessed as individual or aggregates of Conservation Units (CUs), which are genetically or ecologically distinct groups of salmon. CU-specific biological benchmarks, based primarily on salmon abundance and distribution delimit three biological status zones: green (healthy status), amber (intermediate) and red (poor). Here we describe the biological status of each of the five major species in the US and Canada, provide information on changes in fish size and age composition if noteworthy, and comment on possible reasons for recent changes.

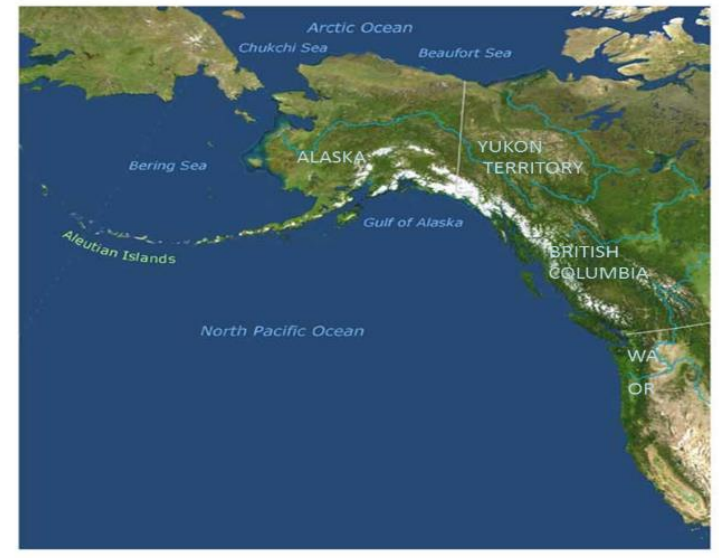

Fig. 1. Eastern North Pacific Ocean showing major locations mentioned in text. Map adapted from: https://www.afsc.noaa.gov/generalinfo/northpacificmap.htm.

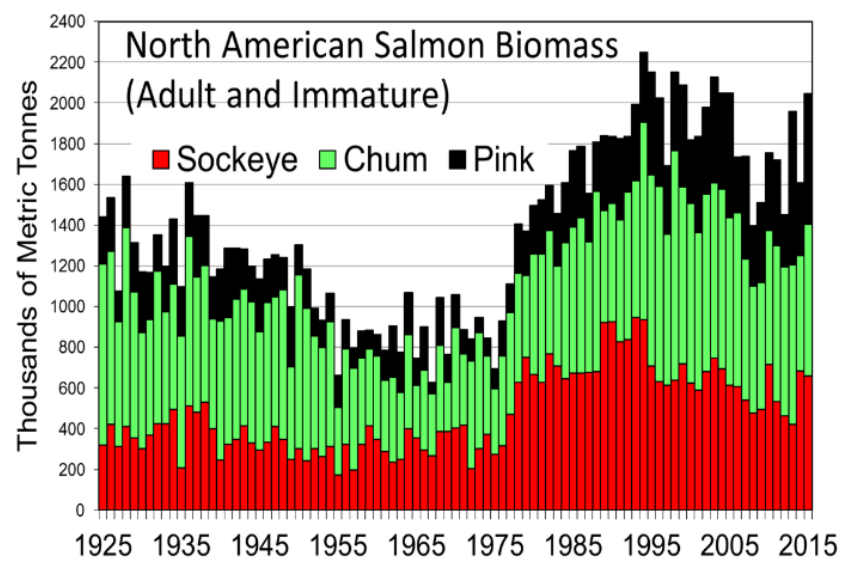

Fig. 2. Biomass of Sockeye, Chum, and Pink Salmon (adult and immature fish combined), 1925-2015. Chinook, Coho, and Steelhead constitute $\sim 5 \%$ of the total and are not shown. Data from Ruggerone and Irvine (2018).

Chinook Salmon are generally doing poorly throughout the eastern North Pacific, suggesting that large-scale environmental processes are primarily responsible for their current status. In Alaska, Chinook Salmon have experienced downturns in abundance over the past two decades. Despite some recent improvements in meeting escapement goals in central and western Alaska, abundances since 2007 have been some of the lowest on record throughout Alaska (Fig. 3, Munro in press). Chinook in the Canadian portion of the Yukon River are also below long-term average levels, and many CUs in southern British Columbia (BC) are in the red zone (Fig. 4, DFO 2016a). In Puget Sound and the Columbia River, wild salmon returns have declined and runs are dominated by hatcheryorigin Chinook Salmon (Fig. 5, Dufault et al. 2018). There has been a shift to younger age classes returning throughout their range with some populations showing decreases in size at age (Ohlberger et al. 2018). 


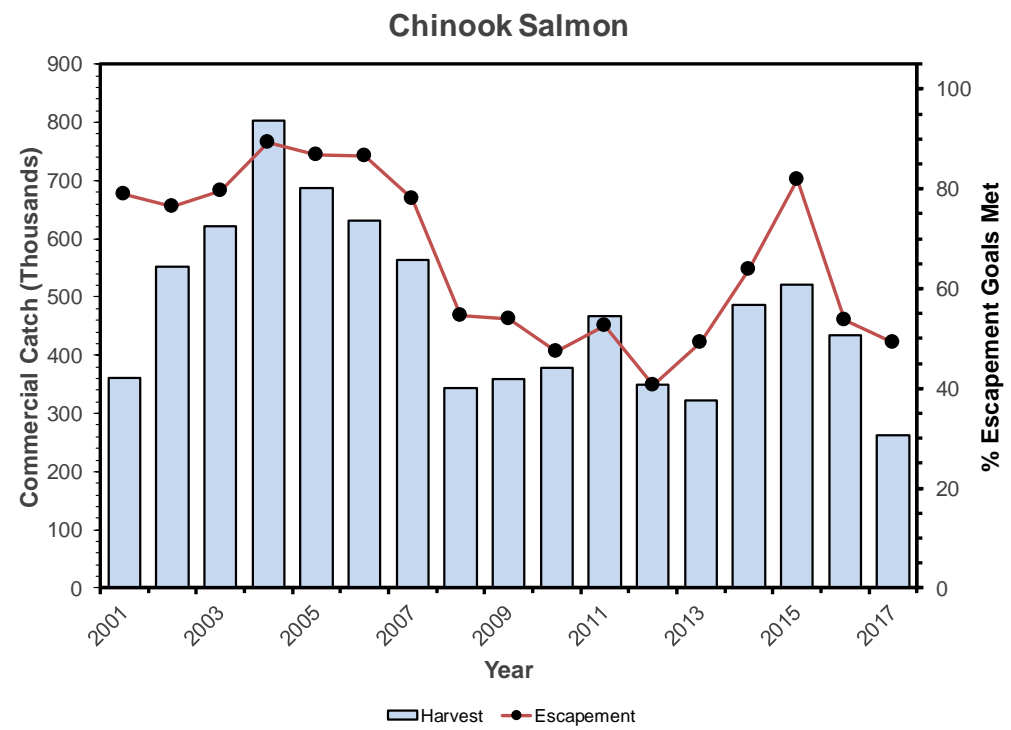

Fig. 3. Annual percentages of Alaska Chinook Salmon stocks achieving escapement goals (adapted from Munro in press) and corresponding commercial harvests (adapted from Brenner et al. 2018).

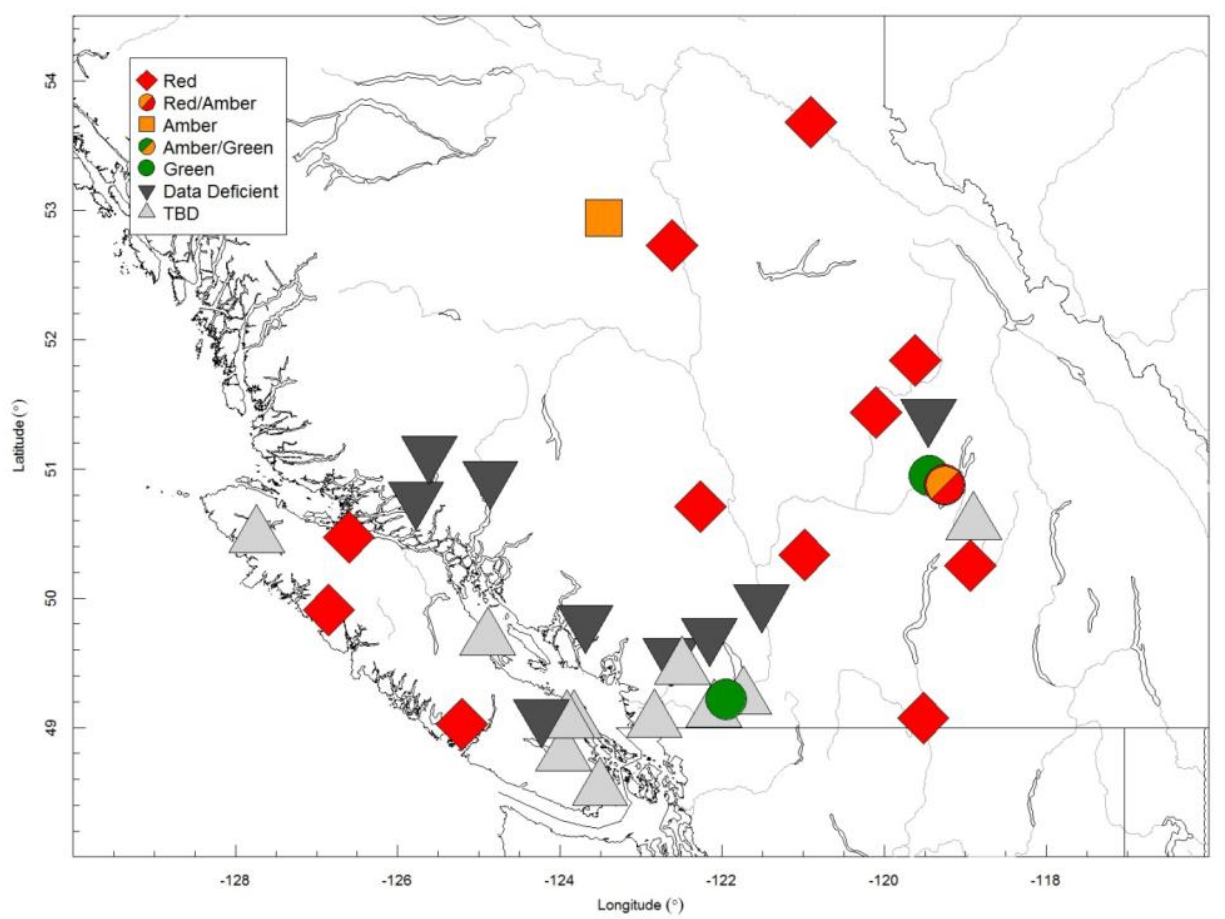

Fig. 4. Map of southern BC summarizing workshop consensus on biological status of southern BC Chinook Salmon CUs. From DFO (2016a).

Sockeye Salmon status is highly variable with populations in the Bering Sea and northern Alaska Current generally doing better than populations in southern BC, implying a potential temperature effect. Interestingly, Sockeye from the Columbia/Okanagan and West Coast of Vancouver Island that enter a different marine ecosystem appear to be responding somewhat differently than more northerly populations, sometimes doing better. Marine growth during odd-numbered years for many Sockeye from Alaskan and some BC populations is reduced compared with growth in even-numbered years, potentially in response to higher numbers of Pink Salmon in odd-numbered years (Ruggerone et al. 2015; 2016). In Alaska, most stocks are in average to good condition with recent increases in commercial harvest and high proportions of escapement goals being met (Fig. 6; Munro in press, Brenner et al. 
2018). High numbers can be associated with reduced growth; recent weights of Bristol Bay and Copper River Sockeye have been well below long-term averages (Fig. 7; ADF\&G, unpublished data). In BC, large returns have generally been associated with La Niña (cool) conditions while poor returns have been linked to El Niño (warm) events. Warm marine and freshwater conditions during 2014-2017 reduced survivals for many populations, particularly for Sockeye returning in 2017. More research is required to fully understand linkages between survival and the frequency and magnitude of ENSO events (Fig. 8, Hyatt et al. 2017).

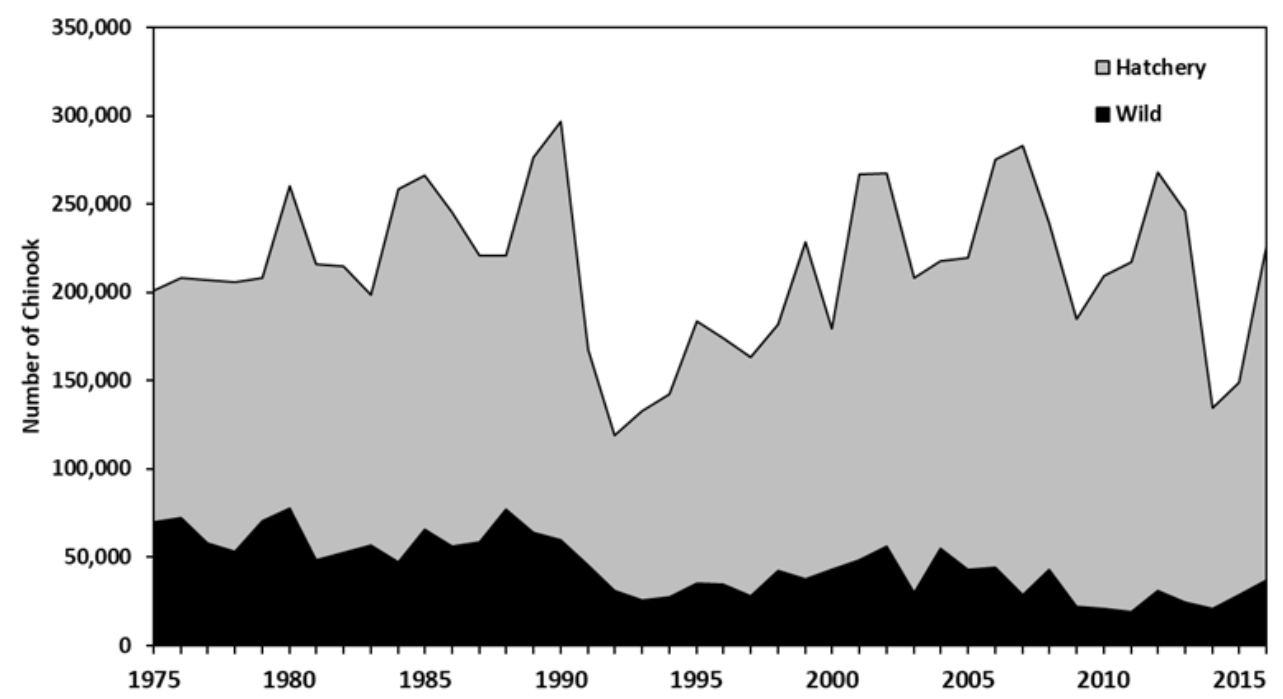

Fig. 5. Numbers of hatchery and wild-origin Chinook Salmon returning to Puget Sound, Washington State (Dufault et al. 2018).

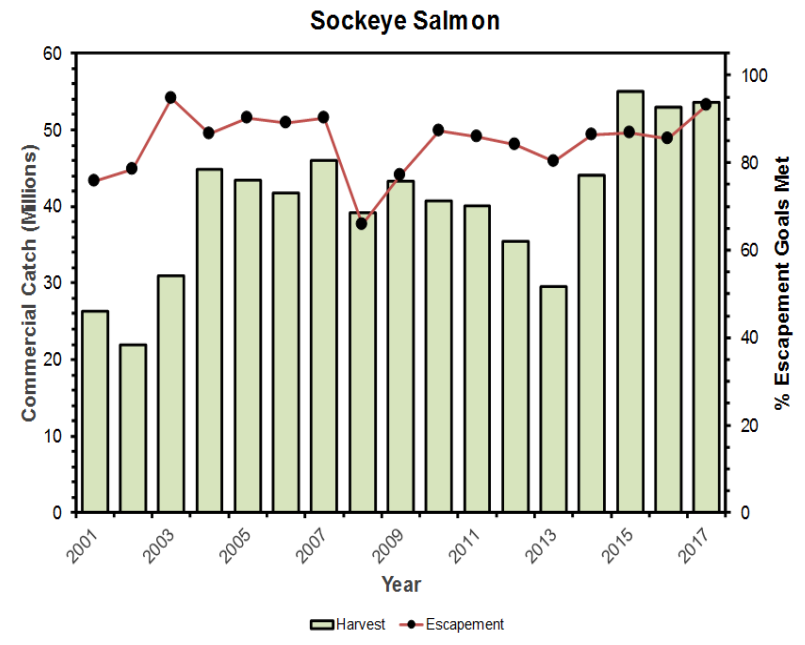

Fig. 6. Annual percentages of Alaska Sockeye Salmon stocks achieving escapement goals (adapted from Munro in press) and corresponding commercial harvests (adapted from Brenner et al. 2018).

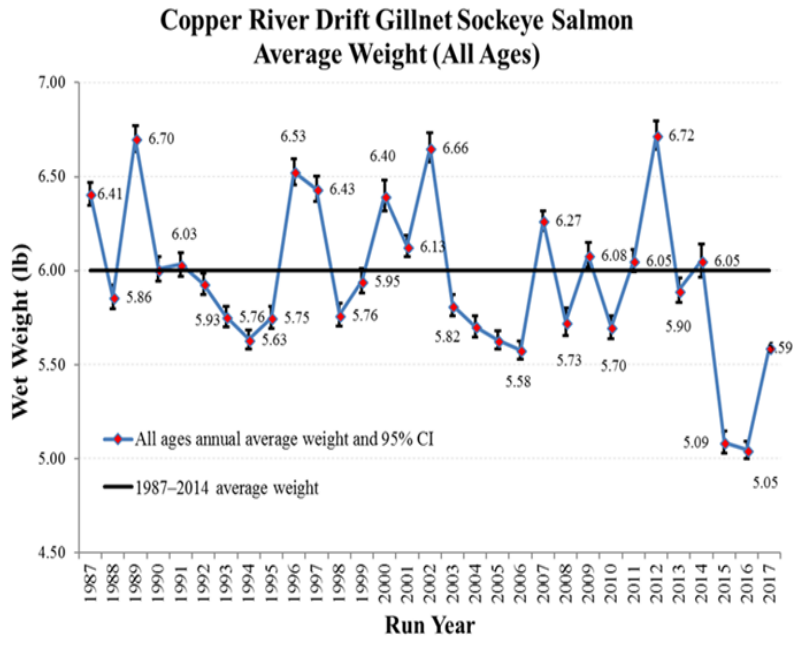

Fig. 7. Average annual weights of Copper River Sockeye Salmon caught in commercial fisheries (S. Haught, ADF\&G, unpublished data). 

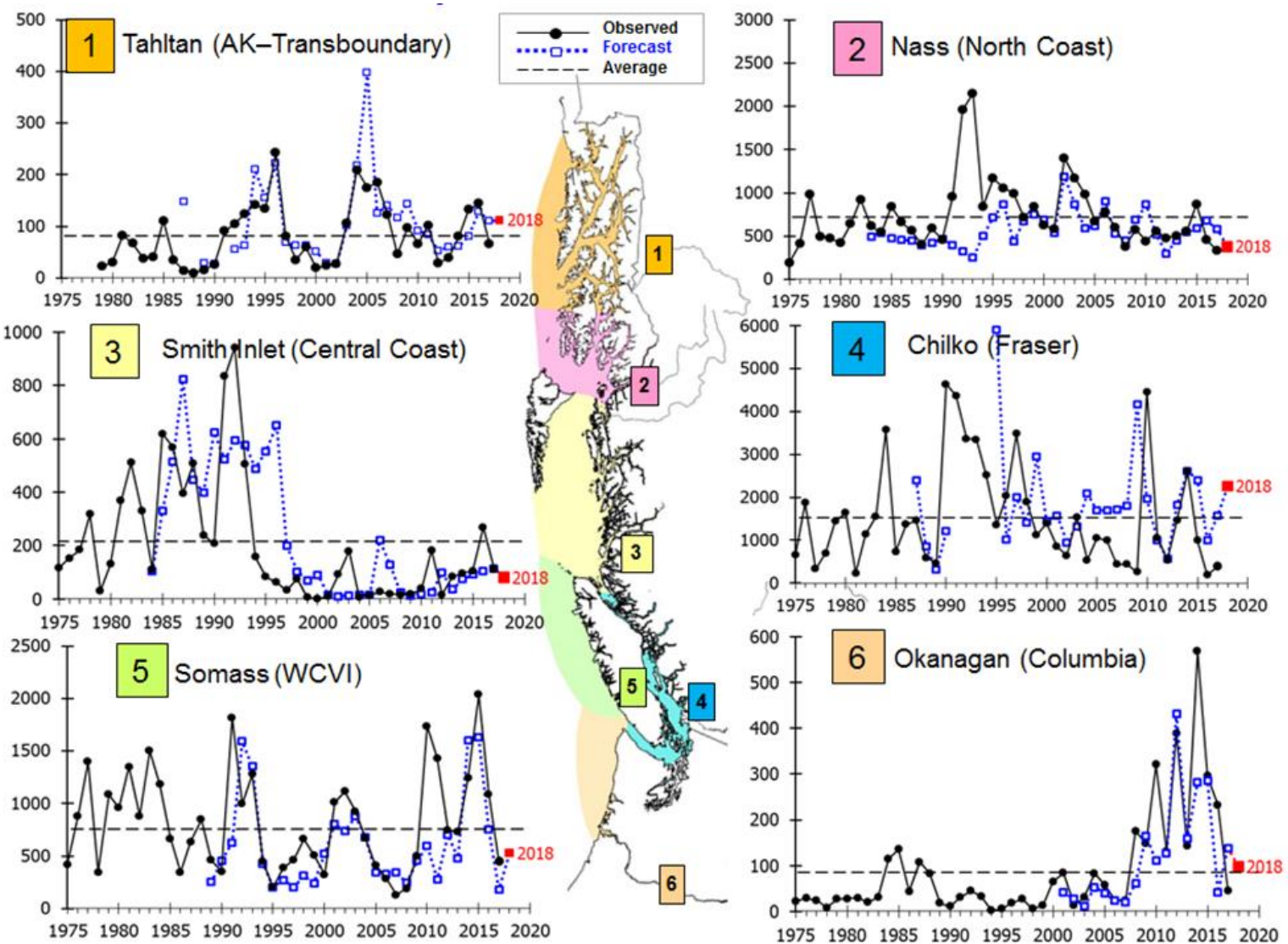

Fig. 8. Trends in the total returns (black line) and resource manager forecasts (blue dashed line) for BC Sockeye Salmon index stocks including: (1) Stikine - Tahltan; (2) Nass-Meziadin; (3) Smith Inlet—Long; (4) FraserChilko; (5) Barkley Sound-Somass; and (6) Columbia-Okanagan. Y-axis represents returns in thousands of fish. From Hyatt et al. (2017).
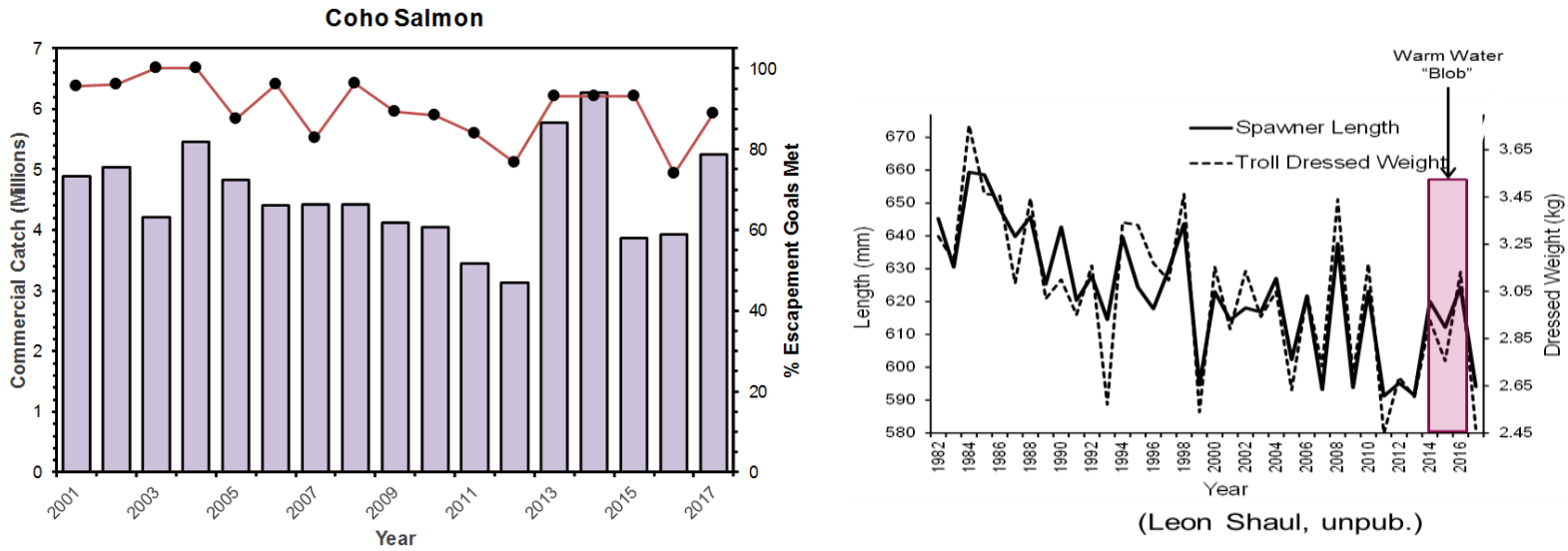

Fig. 9. Annual percentages of Alaska Coho Salmon stocks achieving escapement goals (adapted from Munro in press) and corresponding commercial harvests (adapted from Brenner et al. 2018).

Fig. 10. Declines in lengths of spawners and weights of commercially caught Coho Salmon in Southeast Alaska (Leon Shaul, unpublished)

Coho are perhaps the most difficult salmon species to assess since they return late in the season and do not aggregate in large groups. In most of Alaska, escapement goals have usually been achieved in recent years (Fig. 9; Munro in press). However, Coho have been returning at smaller sizes for the past 3 decades, and, similar to Sockeye Salmon, Coho often return at smaller sizes in odd-numbered than even years (Fig. 10; L. Shaul, 
leon.shaul@alaska.gov, personal communication). In BC, Coho Salmon are generally doing less well in southern regions than northern regions and those from the interior Fraser River watershed are doing the poorest (e.g., DFO 2016b, DFO 2018). Survivals of hatchery and naturally produced Coho Salmon smolts entering the Salish Sea (Canada's Strait of Georgia and US Puget Sound) have declined over the past 3 decades, in contrast to other Coho Salmon that enter outside waters, suggesting that changing conditions early in the marine lives of Salish Sea Coho may be particularly important in determining brood stock strength (Fig. 11, Zimmerman et al. 2015).
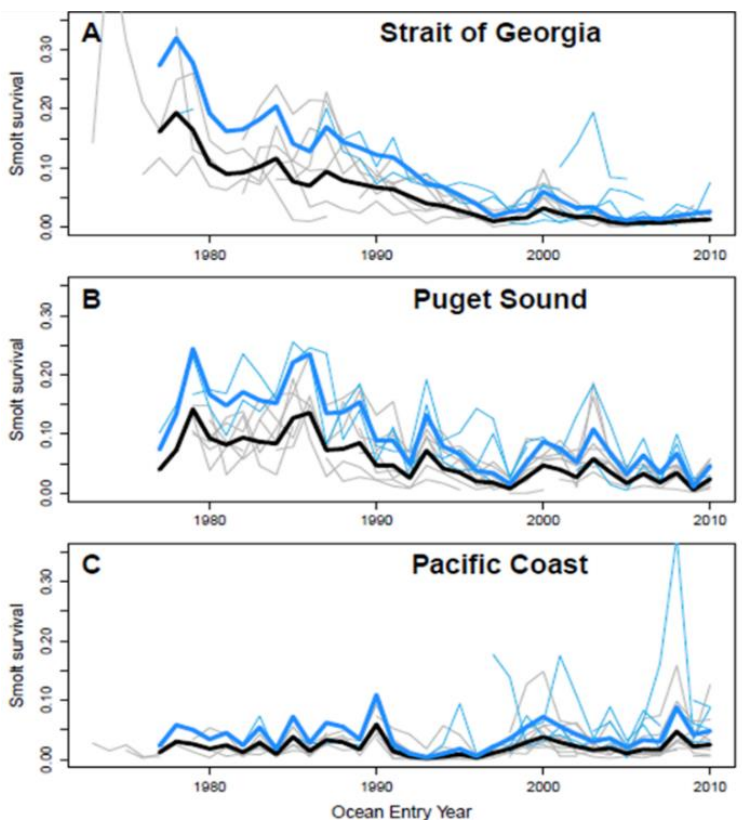

Fig. 11. Coho Salmon smolt survival time series for ocean entry years 1977 to 2010 for (A) the Strait of Georgia, (B) Puget Sound, and (C) the Pacific coast. The thin lines represent individual populations: the thin gray lines are hatchery populations and the thin blue lines are wild populations. The thick lines show the predicted survival for hatchery (black) and wild (blue) populations in each region. From Zimmerman et al. (2015).

Status and returns of Pink Salmon often differs between genetically distinct even- and odd-year brood lines. In Alaska, most odd-year returning Pink Salmon have been meeting or exceeding escapement goals while providing large harvests. There has, however, been a decline in the proportion of escapement goals met for even-year returning Pink Salmon, which has also coincided with low harvests (Fig. 12, Munro in press, Brenner et al. 2018). In BC, returns of odd-year brood line have tended to be stable or increasing while even-year fish populations are stable or declining (Fig. 13, Irvine et al. 2014).

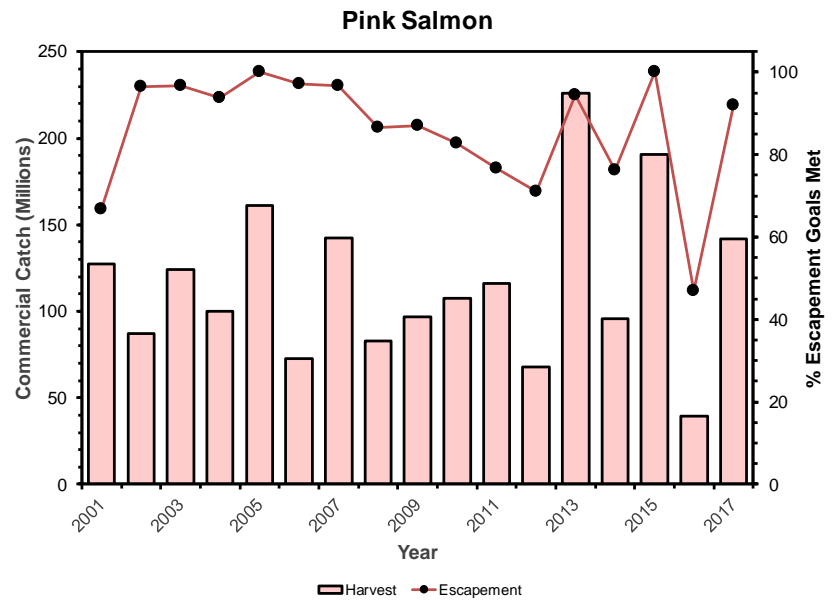

Fig. 12. Annual percentages of Alaska Pink Salmon stocks achieving escapement goals (adapted from Munro in press) and corresponding commercial harvests (adapted from Brenner et al. 2018). 


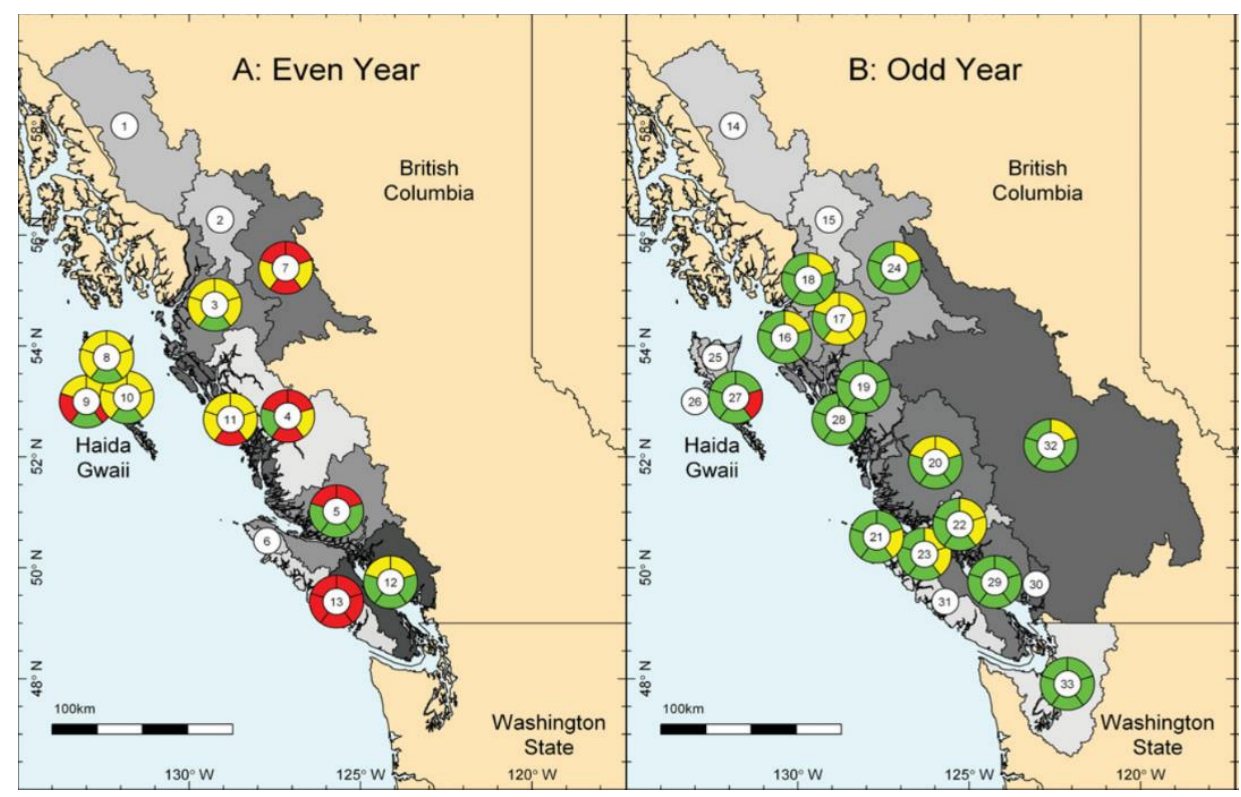

Fig. 13. Status of (A) even-year and (B) odd-year Conservation Units (CUs) of Pink Salmon depicted by fivepiece circles in which the central number is the number of the $\mathrm{CU}$ and each piece shows the results from one time series approach. The colors represent different status zones. Each circle is placed in the area of the freshwater distribution of that CU. From Irvine et al. (2014).

Chum Salmon are generally doing well throughout their range. In Alaska, the majority of stocks currently achieve their escapement goals (Munro in press) and commercial harvests remain high (Fig. 14; Brenner et al. 2018). Chum Salmon tend to be doing less well in northern BC than in the south, although there are exceptions. There is some evidence of an interaction between density and climate effects on marine growth for Chum Salmon in southern BC (Debertin et al. 2017). Numbers of Chum Salmon in Puget Sound, Washington State remain high (Fig. 15, Dufault et al. 2018).
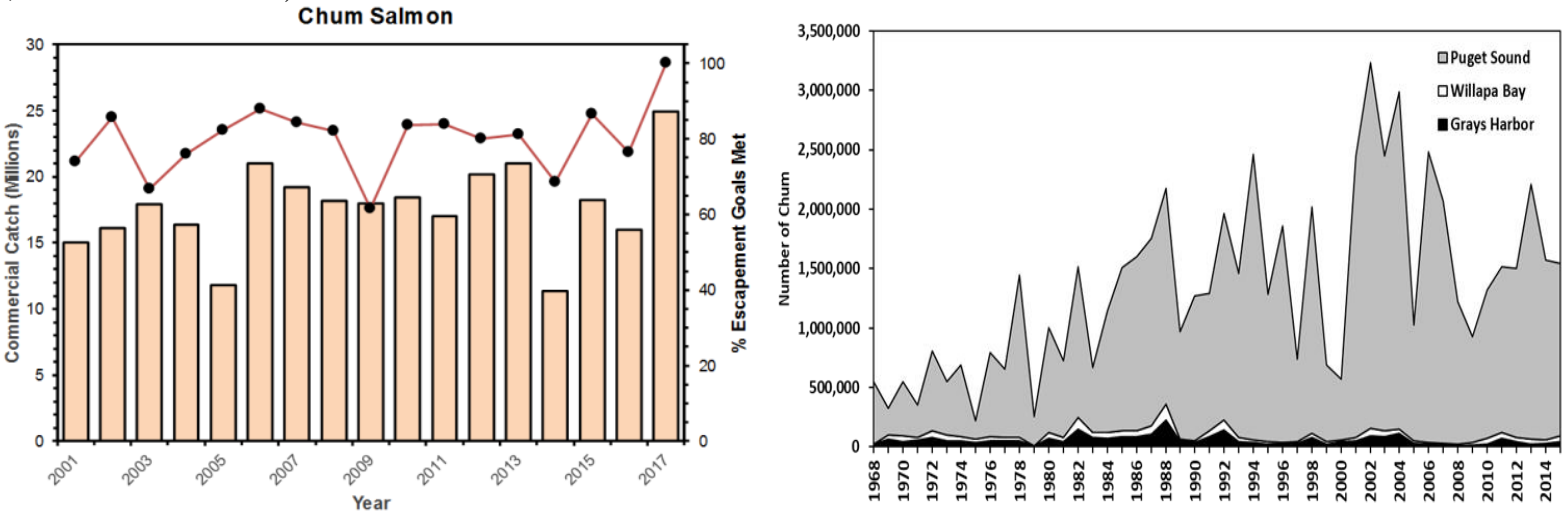

Fig. 14. Annual percentages of Alaska Chum Salmon stocks achieving escapement goals (adapted from Munro in press) and corresponding commercial harvests (adapted from Brenner et al.

Fig. 15. Numbers of Chum Salmon returning to streams in Puget Sound, Willapa Bay, and Grays Harbor, Washington State (Dufault et al. 2018). 2018). 


\section{REFERENCES}

Brenner, R.E., A.R. Munro, and J.C. Shriver (Editors). 2018. Run forecasts and harvest projections for 2018 Alaska salmon fisheries and review of the 2017 season. Alaska Department of Fish and Game, Special Publication No. 18-09, Anchorage. http://www.adfg.alaska.gov/FedAidPDFs/SP18-09.pdf

Debertin, D.J., J.R. Irvine, C.A. Holt, G.Oka, and M.Trudel. 2017. Marine growth patterns of southern British Columbia chum salmon explained by interactions between density-dependent competition and changing climate. Can J Fish Aquat Sci. 74: 1077-1087 (2017) dx.doi.org/10.1139/cjfas-2016-0265.

DFO (Fisheries and Oceans Canada). 2016a. Integrated biological status of Southern British Columbia Chinook Salmon (Oncorhynchus tshawytscha) under the Wild Salmon Policy. DFO Can. Sci. Advis. Sec. Sci. Advis. Rep. 2016/042.

DFO. 2016b. Proceedings of the Pacific regional peer review of the Assessment of Interior Fraser River Coho Salmon Conservation Units' Benchmarks and Status; November 6-7, 2014. DFO Can. Sci. Advis. Sec. Proceed. Ser. 2016/055.

DFO. 2018. Framework for Determination of Pacific Salmon Commission Reference Points for Status Determination and Associated Allowable Exploitation Rates for Select Canadian Southern Coho Salmon Management Units. DFO Can. Sci. Advis. Sec. Sci. Advis. Rep. 2018/016.

Dufault, A.M., M.N.C. Litz, and R. Lothrop. 2018. Washington Department of Fish and Wildlife 2018 North of Falcon Salmon Forecasts. https://wdfw.wa.gov/

Hyatt, K. D., M.M. Stockwell, A. Ogden, and H. Stiff. 2017. Sockeye Salmon indicator stocks—Regional overview of trends, 2016 returns, and 2017-2018 outlook. In: Chandler, P.C., King, S.A., and Boldt, J. (Eds.). State of the physical, biological and selected fishery resources of Pacific Canadian marine ecosystems in 2016. Can. Tech. Rep. Fish. Aquat. Sci. 3225: vi + 243 p.

Irvine, J.R., C.J.G. Michielsens, M. O'Brien, B.A. White and M. Folkes. 2014 . Increasing dominance of odd-year returning Pink Salmon. Trans. Am. Fish. Soc. 143:4, 939-956, doi: http://dx.doi.org/10.1080/00028487.2014.889747

Munro, A.R. In press. Summary of Pacific salmon escapement goals in Alaska with a review of escapements from 2008 to 2016. Alaska Department of Fish and Game, Fishery Manuscript Series, Anchorage, AK

Ohlberger, J., E.J. Ward, D.E. Schindler, and B. Lewis. 2018. Demographic changes in Chinook salmon across the Northeast Pacific Ocean. Fish Fisheries, 19:533-546. https://doi.org/10.1111/faf.12272

Ruggerone, G.T., and B.M. Connors. 2015. Productivity and life history of sockeye salmon in relation to competition with pink and sockeye salmon in the North Pacific Ocean. Can. J. Fish. Aquat. Sci. 72: 818-833. dx.doi.org/10.1139/cjfas-2014-0134

Ruggerone, G.T., B.A. Agler, B.M. Connors, E.V. Farley, Jr., J.R. Irvine, L.I. Wilson, and E.M. Yasumiishi. 2016. Pink and sockeye salmon interactions at sea and their infl ence on forecast error of Bristol Bay sockeye salmon. N. Pac. Anadr. Fish Comm. Bull. 6: 349-361. doi:10.23849/npafcb6/349.361

Ruggerone, G.T., and J.R. Irvine. 2018. Numbers and Biomass of Natural- and Hatchery-Origin Pink Salmon, Chum Salmon, and Sockeye Salmon in the North Pacific Ocean, 1925-2015. Marine and Coastal Fisheries: Dynamics, Management, and Ecosystem Science 10:152-168. doi: 10.1002/mcf2.10023

Zimmerman, M.S., J.R. Irvine, M. O’Neill, J.H. Anderson, C.M. Greene, J. Weinheimer, M. Trudel, and K. Rawson. 2015. Spatial and temporal patterns in smolt survival of wild and hatchery Coho Salmon in the Salish Sea. Marine and Coastal Fisheries, 7:1, 116-134, doi: 10.1080/19425120.2015.1012246 